\title{
PUBLICAÇÕES RECEBIDAS
}

Recebemos e agradecemos:

Armamento Hospitalat no Brasil - Publicação da Divisão de Organização Hospitalar do Departamento Nacional de Saúde do Ministério da Saúde. Río de Janciro, Brasil.

Boletin Informativo - Noticias institucionales, cientificas, artisticas, bibliograficas, etc. $N^{\circ} 5-2^{3}$ série - Marzo/Abril 1959. Santa Fé, Argentina.

Boletım Mensal - da Federação das Indústrias do Distrito Federal - Departamento de Produtividade. Ni 55 - Junho de 1959. Rio de Janeiro, Brasil.

Crônica de la Unesco - Boletin mensual publicado por el Centro Regional de la Unesco en el Hemisferio Occidental. Vol. $\mathrm{V}-\mathrm{N}^{\circ} 4-$ Abril, 1959. La Habana, Cuba.

de Portugal Para o Brasil - Publicação do Escritório de Propaganda e Expansão Comercial do Brasil em Lisboa. Ano XI - N 3 - Março de 1959. Lisboa, Portigal.

Livros de Portugal - Boletim mensal do Grêmio Nacional dos Editôres e Livreiros - Novidades - Ecos - Bibliografia. No 6 - Junho, 1959. Lisboa, Por tugal.

Notícia Geomorfológica - Noticias, resumos, transcrições selecionadas, bibliografias, critica. Ano II - N 3 - Abril de 1959. Campinas, São Paulo, Brasil.

Servicios Publicos - Mayo/Junio 1959. La Habana, Cuba.

La Scienza Tecnica della Organizzazzione nelle Publiche Amministrazioni - Rivista trimestrale per il miglioramento dell'azione amministrativa. Anno IV $-\mathrm{N}^{\circ} 4-$ Ottobre-Dicembre 1958. Milão, Itália.

Saúde - Publicação de caráter popular do S.N.E.S. Ano XII - Março 1959 $\mathrm{N}^{\circ}$ 135. Rio de Janeiro - Brasil.

Saúde e Trabalho - Mensário de doutrina e prática de higiene e segurança do trabalho. Ano V - Maio, 1959 - No 51

Rio de Janeiro, Brasil.

Revista Ceres - Publicação de ensinamentos teóricos e práticos sôbre agricultura, veterinária, indústrias rurais. $N^{\circ} 60-$ Volume X - Janeiro a Abril de 1959. Viçosa, Estado de Minas Gerais, Brasil.

Revista da Escola de Minas - Publicação técnica sob os auspícios do Diretório Acadêmico da Escola Nacional de Minas e Metalurgia da Universidade do Brasil. Vol. XXI - No 5 - Junho de 1959. Ouro Prêto, Minas Gerais, Brasil.

Revista de Finanças Públicas - Editada pelo Conselho Técnico de Economia e Finanças do Min'stério da Fazenda. Ano XIX - $\mathrm{N}^{\circ} 206$ - Abril/Maio de 1959. Rio de Janeiro.

Revista Fiscal e de Legislação de Fazenda - Publicação quinzenal, sistematizada e com explicações e comentários das leis. decretos e decisões administrativas e judiciárias, sôbre matéria fazendária. Ano XXX - Ns. $7-8$ - 30 de Junho de 1959. Rio de Janeiro, Brasil.

Revista do IRB - Publicação bimestral do Instituto de Resseguros do Brasil. Ano XX - No 115 - Junho de 1959. Rio de Janeiro.

Revista Paulista de Contabilidade - Órgão do Sindicato dos Contabilistas de São Paulo. Revista de Contabilidade, Economia, Direito, Finanças, Estatística. Ano XXXVII - $\mathrm{N}^{\circ} 365$ - Jan./Abril de 1959. São Paulo, Brasil.

Revista do Trabalho - Ano XXVII Março/Abril de 1959. Rio de Janeiro, Brasil.

Revista da Universidade Católica de São Pattlo - Publicação trimestral que tem por finalidade difundir o pensamento católico e divulgar os resultados da investigação cientifica das Unidades Universitárias. Vol. XVII - Fascículo 29 - Março de 1959. São Paulo, Brasil.

Revue Internationale des Sciences Administratives - Vol. XXV - No $1-1959-$ Bruxelles, Belgique. 